\title{
A construção do perfil do professor e a mediação didática lúdica no Ensino Fundamental II
}

\begin{abstract}
Resumo: O artigo traz resultados de pesquisa realizada em 2016 com professores que tiveram uma história de vida marcada pela leitura literária e em consequência, estabelecem mediações de leitura em ambiente escolar no Ensino Fundamental II. A pesquisa foi realizada com uma professora e um professor de escolas públicas, uma em Salvador e outra em Feira de Santana, mediante abordagem fenomenológica, utilizando histórias de vida, com o auxílio dos instrumentos: observação participante, entrevista narrativa e texto autobiográfico. Os professores participantes da pesquisa são licenciados em Biologia e Matemática. A ludicidade como premissa fundante da experiência com a leitura literária na vida dos sujeitos foi investigada, assim como, a sua expressão lúdica foi observada nas mediações didáticas e partilhas espontâneas de saber literário. Concluiu-se que o "eu lúdico", como impulso inicial do sujeito, mediante contínuas experiências afetivas com a leitura literária, concretiza um perfil profissional, que, por sua vez, influencia a forma e a qualidade das mediações didáticas.
\end{abstract}

Palavras-chaves: Leitura Literária. Ludicidade. Mediação Didática. Histórias de vida.

\section{Introdução}

No final da década de 1970 e durante a década de 1980, as discussões sobre a importância da leitura literária nas escolas tomaram corpo entre intelectuais e pesquisadores brasileiros. O papel da literatura para um ensino significativo era exaltado num momento de retomada da cultura num país que, após alguns anos em regime de exceção, dava os primeiros passos para uma abertura política e redemocratização. Pesquisadores ligados à formação de pedagogos e professores de Letras mostravam com alarme os índices pífios de leitura no país e começavam a organizar eventos voltados para a leitura.

Após este período de retomada cultural, a economia tornou-se globalizada e o ensino fundamental foi submetido a diversas reformas: algumas mudaram apenas o nome e outras estabeleceram parâmetros curriculares e o sistema de cotas em universidades públicas. No âmbito da cultura, as alterações foram substantivas com o avanço tecnológico e a comunicação eletrônica e em rede em ambiente digital chegando ao que temos hoje: a convergência de mídias em um único aparelho celular. Apesar das mudanças sociais ocorridas nas últimas décadas, a escola pouco mudou no
Sandra C. Popoff

Universidade Federal da Bahia (UFBA)

popoffsandra@gmail.com

Cristina D’Ávila

Universidade Federal da Bahia (UFBA) e Universidade Estadual da Bahia (UNEB)

cristdavila@gmail.com 
que se refere a aprendizagem e a situação do professor. Além disso, o empobrecimento da escola pública tem ficado cada vez mais patente, aumentando assim, o clima de desânimo e naturalização do fracasso escolar.

Zilberman (2008) focaliza a problemática da leitura literária nas escolas públicas de educação básica elencando alguns dos entraves mais frequentes como: a fragmentação do texto literário oferecido em guizados entre as páginas de livros didáticos, não raro, de forma descontextualizada. A literatura adulterada que passou a ser instrumentalizada para o ensino da gramática, na maioria das vezes; a falta de liberdade de escolha dos livros, que um olhar crítico revelaria facilmente uma indústria editorial a negociar os seus produtos diretamente com instâncias governamentais. Às limitações citadas se somam ainda com: leitura literária como território restrito ao trabalho da disciplina de Português e por consequência, com ênfase na gramática normativa e a falta de acesso ao acervo literário organizado nas escolas para o estudante do Ensino Fundamental II. Por outro lado, quando a escola possui uma biblioteca organizada, muitas vezes, o ambiente é pouco acolhedor e com tempo restrito para visitas. Predominam, ainda, as atividades obrigatórias e avaliativas de leitura, questionários prontos fornecidos pelas editoras sem muita liberdade para interpretação, criação e apropriações, a partir do imaginário do leitor; e por fim, o fato de que muitos professores não têm hábitos de ler literatura como fruição de uma linguagem artística.

Todavia, apesar de tantos problemas para uma inclusão correta da literatura nas escolas, ainda há esforços por parte de alguns professores, no sentido de criar uma aproximação do leitor em formação com o universo do livro. Estes professores leitores sujeitos da pesquisa, não possuem formação na área de linguagem, contudo tem a atitude e a paixão necessária para entender o imaginário literário e disposição para partilhá-lo informalmente. Diante deste perfil diferenciado, foram denominados nesta pesquisa com os codinomes: Fada Sorriso e Pequeno Príncipe.

Usar a leitura literária, juntamente com o ensino de outros conteúdos, à primeira vista, pode parecer uma instrumentalização da arte em benefício do didatismo. De fato, aparenta ser um risco, mas, no caso dos professores pesquisados, constatou-se uma aura de paixão pela literatura, que não permite a desvalorização do imaginário literário em prol de um imediatismo pedagogizante. 
O fato da partilha literária acontecer de forma gratuita, sem a intenção de atribuição de notas ou outro tipo de cobranças, tem garantido o seu caráter lúdico, já que a ludicidade pressupõe a liberdade de ação; flexibilidade; relevância no processo; a incerteza de resultados; o controle interno estabelecido tacitamente e também, adesão voluntária. (BROUGÈRE, 1998) Dessa forma, o uso da literatura em contexto didático toma um caráter autêntico, capaz de proporcionar uma transcendência inusitada, no sentido de que a matemática, que pouco compreende a literatura, pode ser compreendida pela ótica da literatura e a amplia em conexões significativas com outros saberes, circunstâncias e dimensões simbólicas. (GOMEZ, 2004)

Podemos dizer que a literatura é naturalmente transdisciplinar, quando abre portais de entendimento para mundos paralelos, simples de serem acessados, porém complexos demais para serem objetos de racionalizações. Dessa maneira, o tema proposto neste trabalho perpassa a leitura literária com Zilbermann (2008), a ludicidade com Luckesi (1998, 2000, 2002, 2004), Brougère (1998, 2002),Callois (1990), os saberes sensíveis com Maffesoli (1998, 2001), e deságua numa bacia semântica de Durand (1997) e na mediação didática lúdica de D'Ávila (2007, 2014, 2016), por ângulos particulares à realidade dos sujeitos da pesquisa.

A pesquisa condensada neste artigo foi desenvolvida entre 2015 e 2016, tendo como colaboradores da pesquisa, um professor de Matemática e uma professora de Biologia, ambos docentes de escolas públicas do Ensino Fundamental II. O objetivo geral foi analisar para compreender como a ludicidade se faz presente na história de vida de professores, como elemento fundante na mediação de saberes literários no ensino fundamental. Para tal, as seguintes etapas específicas foram projetadas: 1) conhecer, mediante história de vida de professoras, suas vivências lúdicas e literárias e relacioná-las a possíveis aportes no ensino da leitura literária; 2) identificar como professores, colaboradores do estudo, inserem atividades lúdicas em suas mediações didáticas; 3) reconhecer, através de suas representações, como a ludicidade pode ser inserida no cotidiano escolar através das leituras literárias. Os objetivos propostos foram alcançados com a utilização dos instrumentos metodológicos: observação participante, entrevista narrativa e texto autobiográfico, em pesquisa de cunho qualitativo e abordagem fenomenológico, a partir de relatos de histórias de vida. 


\section{A escola e o imaginário literário}

Morin (1970), Maffesoli (2004) e Durand (2011) abordaram a questão do imaginário como dimensão dinâmica. Durand (2011) formula o conceito de bacia semântica como um escoamento imagético contínuo, onde o imaginário familiar exerce pressão e modula transformações no imaginário coletivo. Maffesoli (2004) atribui à inundação da bacia semântica, a capacidade de originar um rio de continuidades, descontinuidades e recontinuidades, que renascem em ciclos que se perdem no mar do imaginário coletivo. Para Morin (1970, p. 251) este mesmo "[...] imaginário confunde numa mesma osmose, o real e o irreal, o fato e a carência, não só para atribuir à realidade os encantos do imaginário, como para conferir ao imaginário as virtudes da realidade" no esforço de dar conta da complexidade tão humana de imaginar e gerar sentidos.

O imaginário alimenta-se de memória, portanto de passado como afirma Bosi (2003, p.16) "[...] do vínculo com o passado se extrai a força para a formação de identidade", assim, não é possível buscar as paixões que movem pessoas e se oferecem como agentes de transformação sem considerar as pressões em torno das imagens internas e suas aplicações externas. Estas conceituações confirmam-se adequadas para a análise dos primeiros dados colhidos junto a Fada Sorriso, em seu relato inicial sobre a sua história com a leitura literária. Os pais eram semianalfabetos, no que se refere à educação formal, contudo não negligenciaram uma iniciação literária e artística como podemos verificar:

Meus pais eram semianalfabetos: minha mãe era bordadeira e costureira e o meu pai motorista de ônibus. Davam muita importância à educação escolar e doméstica. Eu tenho certeza que tive o melhor. Os dois incentivavam a leitura dentro do lar. No ambiente doméstico tudo favorecia a leitura: a estante de livros e a cadeira do papai era muito aconchegante. Meu pai era freguês dos vendedores ambulantes de enciclopédias. Eu lia e relia incansavelmente sentada na cadeira do papai (FADA SORRISO).

A relação de afeto com a leitura literária na história de Fada Sorriso tem o poder de alargar as suas relações interpessoais e posteriormente, determinou a escolha da profissão - a Biologia - por causa do amor à natureza, despertado por textos lidos por escolha própria e em atmosfera de emoção. O relato serve para 
esclarecer a escolha dos mesmos textos para a utilização em sala de aula, lido para os alunos com entusiasmo contagiante:

Certa vez, quando criança, fui passar férias em Salvador e tive uma experiência de leitura emocionante com o enredo do Meu Pé de Laranja Lima do José Mauro Vasconcelos. Eu e Cláudia, minha amiga, nos revezávamos na leitura de cada capitulo e as lágrimas rolavam pelas perdas e mortes vivenciadas pelo menino Zezé e o seu Minguinho - o pé de laranja lima. Foi este livro que despertou o meu amor pela natureza. Um dia, já professora, li um texto do Humberto de Campos - 'O meu cajueiro'e senti a mesma emoção despertada pelo livro do José Mauro (FADA SORRISO).

O texto literário é território propício ao saber sensível, além de criador de sentidos e espaço de experimentação fundamental à recuperação da inteireza do indivíduo no coletivo. Este exercício insere o sujeito na esfera da alteridade, enquanto toma para si vivências de outros. Barthes (1980) declara que a literatura é fundamental e não pode desaparecer do currículo, porque abre portas para muitas outras disciplinas.

Lajolo (2001, 2006), pesquisadora da leitura no Brasil, por sua vez, denuncia a leitura obrigatória como fardo pesado que impede a fruição e o prazer, sendo defensora da leitura facultativa ou por livre escolha, como um direito do estudante, e, ainda, alinha-se a Pennac (1993) em seu decálogo dos direitos imprescindíveis do leitor, que são: o direito de não ler; o direito de pular páginas; o direito de não terminar um livro; o direito de reler; o direito de ler qualquer coisa; o direito ao bovarismo; o direito de ler em qualquer lugar; o direito de ler uma frase aqui e outra ali; o direito de ler em voz alta; o direito de calar.

É necessário repensar o motivo da tácita restrição do exercício literário estar "oficialmente" ligado ao estudo da gramática da língua, a partir do ingresso do estudante no ensino fundamental e mais, questionar o motivo de não ser prática estabelecida na comunidade escolar, recorrer aos mediadores apaixonados por leitura, independentemente da formação ou função na escola. Estes direitos revolucionários opõem-se à realidade da prática de leitura mais comum em ambiente escolar. Diante disso, conciliar o saber estabelecido e condensado em grades curriculares e a construção do conhecimento mediado pela ludicidade, desafia educadores reflexivos. 
Os professores pesquisados usam recursos internos que determinam a qualidade da escuta com intenso contato visual, sorriso autêntico (pálpebras relaxadas e olhos brilhantes) e atitude de interação intensa que vem a ser o primeiro passo da conquista do estudante para a mediação didática fluída, que foi muito agradável de observar e fruir. Os recursos externos (objetos lúdicos), quando são usados, parecem ser consequência dessa sintonia com a intenção e reforçadores do ritmo que se quer empregar, porém nos casos pesquisados só houve referências a esses objetos nas falas de Fada Sorriso, quando menciona fantasias para a representação teatral das histórias lidas. Assim, a leitura literária não pode ser ensinada como conhecimento estático ou formal, senão como uma das expressões da criatividade humana. Tais como obras de arte, a poesia e a ficção trazem em si um potencial que permite ao sujeito a interação, a fruição do belo e a reflexão sobre o mundo e sobre si próprio. Do olhar reflexivo sobre a arte literária surgem ferramentas para uma leitura crítica do mundo.

Partindo das premissas elencadas, temos a questão da didática tradicional, avaliativa em excesso, instada a abrir caminho para critérios diferenciados para o ensino ou vivência literária em ambiente escolar. Também, pensamos que o aprendizado proporcionado pela arte literária tem um caráter preponderantemente subliminar, cumulativo e sensibilizante, que conduz ao refinamento do pensar e do sentir. Diferente do texto didático que possui características formais permitindo assim, avaliações mais diretas. Porém, não se pode esquecer que a escola ainda é o lugar primordial da leitura no Brasil e até mesmo o livro didático pode ser o suporte para uma iniciação de leitura literária, conforme nos informa, o colaborador da pesquisa, Pequeno Príncipe, que diz:

\begin{abstract}
A minha história com a leitura não veio inicialmente no seio familiar. Meus pais não tiveram um acesso à educação de forma devida. As oportunidades não eram como as de hoje. Então se estudava minimamente. Meu pai estudou até a $4^{a}$ série e a minha mãe até a $5^{a}$ série. O meu primeiro contato com a leitura foi na escola. E na escola também não foi com livros paradidáticos, que seria o ideal para a idade, mas sim, aproximação com a leitura foi a partir do livro didático.
\end{abstract}

No imaginário coletivo moderno, a escola é reconhecida como uma instituição onde se dá a educação e, poucas pessoas refletem sobre a diferença entre o que vem a ser educação e um 
sistema de ensino, por exemplo. Apesar disso, nem mesmo os inúmeros fracassos conseguem tirar da escola, a supremacia oficial da distribuição dos conhecimentos. Contudo, a escola necessita reposicionar-se a respeito de práticas importantes, dentre elas, a mediação da leitura literária e a ludicidade como componente de uma didática comprometida com o desenvolvimento da potencialidade humana.

\section{A construção do perfil lúdico de professores leitores}

Ludicidade, brincadeiras, brincar, jogos, lazer, diversão, recreação são fenômenos que coexistem na fronteira tênue de conceitos polissêmicos, que cobrem áreas correlatas, mas não são sinônimos, podendo, assim, gerar interpretações conflitantes. Inicialmente, se faz necessário esclarecer o que entendemos por ludicidade no presente estudo, pois não esperávamos encontrar atividades lúdicas (brincadeiras, por exemplo) na mediação dos professores estudados, mas, certa atitude que emana de um ser em plena satisfação com a própria história leitora, ou seja, uma atitude lúdica de comprometimento que gera alteridade.

Luckesi inovou o estudo da ludicidade, tornando-o mais abrangente e inclusivo, para abordagens de todo o fazer humano. Entendemos a ludicidade sob o ponto de vista de Luckesi (1998, 2000, 2002, 2004), como experiência de plenitude e inteireza do ser e neste estudo a relacionamos com a fruição estética da leitura literária, acreditando que ler para alguém representa uma expressão de amor e de esperança na humanidade. Esse conceito de ludicidade não se restringe ao divertimento, mas é propiciadora de uma conexão profunda e harmônica entre a mente, as emoções e o corpo. Esta plenitude lúdica do ser desenvolvida conceitualmente por Luckesi nos dá condições de analisar essa conexão, em que Fada Sorriso menciona experiências sensoriais positivas e as relaciona com a literatura infantil. Esta forma de fruição literária, por sua vez, terá um papel importante na forma de partilha que fará dos textos literários, as "gostosuras" oferecidas aos estudantes. O relato traz as suas primeiras memórias dos livros infantis:

Minha mãe sempre trazia do mercado alguma estorinha ou um conto de fada - A sementinha bailarina, D. Baratinha, Chapeuzinho Vermelho, e outras... eram gostosuras que também alimentavam e chegavam com as compras de alimentos (FADA SORRISO).

revista entreideias, Salvador, v. 7, n. 1, p. 153-170, jan./jun. 2018 
A consciência da arte literária e do espaço para a sua fruição, o gosto pela leitura vivenciado por crianças em ambiente escolar, negligenciada muitas vezes, pertence ao educando e deve mobilizá-lo, na condição de mediador de saberes sociais. Um dos autores que tomamos para este alargamento das apreensões e reflexões é Maffesoli (1998, p. 21-22) do qual citamos trecho para aclarar este ensejo de reflexão:

Há aí um fecundo ensejo à reflexão. As coisas e as pessoas são o que são, procedem e organizam-se de acordo com uma disposição que lhe é própria. Assim, em vez de desejar pegá-las no conceito, talvez valha mais a pena acompanhar a energia interna que está em ação em tal propensão.

A leitura perpassa todo o fazer escolar e ultrapassa-o como fundamento de aprendizagem para a vida. Diante do quadro das características da leitura lúdica, as fadas da leitura - professores apaixonados por literatura - parecem apontar para uma terceira via na construção de uma didática lúdica, que nada mais é do que a didática do sensível ou raciovitalista. (D'ÁVILA, 2016) Assim, a leitura lúdica constitui-se como ato de ler que, além de decifrar os códigos formais da língua-lida ou ouvida, escrita ou narrada propicia ao leitor uma gama de atribuições de significados permeados pela cultura, contexto e experiência com as emoções e afetos suscitados pela leitura e pela mediação didática. (FREIRE, 2001)

A leitura lúdica, proporcionada pela mediação tal qual descrevemos, transcende o estímulo inicial do texto e possibilita conexões da cognição com a emoção, resultando em bem-estar físico e espiritual. Acrescenta-se ainda, o fato de promover a liberação da criatividade mediante a elaboração de imagens mentais e marcos afetivos que operam na construção da identidade. É um tipo de conhecimento integrativo - corpo, mente, emoções (DUARTE JÚNIOR, 2000) construído e apropriado pelo indivíduo, enquanto reconhece as veredas subjetivas, a partir do ato de ler como opção artística.

Nos relatos do sujeito Pequeno Príncipe, há uma nota de empolgação ao lembrar de um livro marcante: "O primeiro livro que eu li, após o contato com os didáticos foi $\mathrm{O}$ pequeno príncipe de Saint Exupery". Este livro e seu personagem, o pequeno visitante interplanetário, foi uma das referências mais carregadas de força no seu referencial literário. Desta maneira, foi possível 
considerar a paixão elementar, fundante ao próprio ser, no processo de constituir-se e traduzir-se. Por sua vez, Fada Sorriso elabora a sua história com impressões, percepções e sutilezas coletadas no ler, no ouvir histórias e na relação episódica com a literatura como uma hiper-realidade organizadora de repertórios lúdicos de grande carga afetiva.

Desta forma, as adjetivações normalmente atribuídas à ludicidade: ação e adesão voluntária, imbricadas com a leitura ajudam a formular o que pretendemos dizer com leitura lúdica. O fenômeno da ludicidade, segundo Lopes (2004) possui uma natureza consequencial, ou seja, assim como se dá com o fenômeno da comunicação, assim, ocorre com a ludicidade, pois esta reside na própria natureza humana e é partilhada por todos ao longo da vida e não somente durante a infância. Os processos relacionais e interacionais, que o ser humano vivencia em sua trajetória podem fornecer o patrimônio lúdico de cada um e a cada comportamento, uma significação lúdica. Portanto, a ludicidade tem uma importância capital na construção da condição do Humano. Para Lopes (2004, p.4), esta condição lúdica propiciadora do Humano tem sido negligenciada e pouco entendida, porém, jamais será insignificante ou poderá ser tratada como "[...] reserva de infância, superficial ou irresponsável". Para além de simples brincadeiras, recreação ou lazer, a "ludicidade é elegância da observação atenta e elegância da escuta ativa" que poderá propiciar significações a partir de comportamentos e processos.

O lúdico, então, nesta abordagem conceitual, habita o processo e independe dos efeitos finais dos mesmos, todavia, estabelece uma rede de compromissos, livremente assumidos, no transcorrer das interações. Segundo Callois (1990) o princípio original do jogo está bipartido em Ludus e Paidia, que situados conceitualmente em polos antagônicos, se presentificam nos jogos em diferentes níveis da escala representada por agôn, alea, mimicry e illinx.

Para Callois (1990) a Paidia reina sobre as manifestações espontâneas do espírito do jogo, tipificando a infância, e tem origem etimológica do nome de raiz grega. Em Paidia temos a liberdade, a fantasia e todo o alvoroço brincante. Ludus, etimologicamente de origem latina por sua vez, tem a forma disciplinada, socializada, regrada e às vezes, estandardizada em seu comportamento. Fazendo alusão ao deus do jogo, Ludus, exerce uma pressão disciplinar sobre Paidia e corresponde à força civilizadora dos valores morais 
e intelectuais própria da cultura estabelecida, dotando todas as categorias de jogos com o seu potencial de excelência e de pureza.

Pequeno Príncipe, mostra um perfil mais aproximado das características de Ludus, quando aconselha as alunas a não perderem tempo dando atenção somente aos livros românticos. A atenção, deve, pois, segundo ele, estar sobre as muitas oportunidades de ser alguém na vida. Para este sujeito da pesquisa, bons livros são os que dão uma visão maior para a conquista dos objetivos. Para ilustrar conta um episódio emblemático:

Um dia vi uma aluna chamada Larissa lendo, então eu a chamei e comecei a investir na sua formação. Marquei com ela no sábado e a preparei para saltos maiores. Refiz provas de concursos com ela e pronto, ela está no IFBA e já pensando numa graduação. A leitura neste contexto (escola pública) precisa ir além do paradidático. Temos que dar aos estudantes acesso a boa leitura para que amadureçam e possam equiparar-se a países mais desenvolvidos (PEQUENO PRÍNCIPE).

O caminhar da Fada Sorriso por obras, autores e os seus textos preferidos lembram a classificação de Roger Callois (1990) para Paidia, que representa o comportamento expansivo da exuberância, a alegria espontânea e da diversão contagiante em oposição complementar com Ludus, que, no outro extremo da escala representa o comedido, o que tem regras estabelecidas, o jogo controlado. A manifestação lúdica da Fada Sorriso nas relações com a literatura e nos contágios que promove do ato de ler demonstra pura paixão quando diz: "Parafraseando Rubem Alves, eu acho que a leitura tem que ser vagabunda, né". Nessa alusão, Fada Sorriso quer dar conta de uma visão de relaxamento, prazer e espontaneidade em relação a fruição literária, porém o cuidado meticuloso com que prepara atividades e textos e livros a compartilhar, demonstra que essa espontaneidade nada tem de espontaneísmo ou improviso.

A condição lúdica do ser, longe de ser uma dimensão menor e passageira, reserva da infância (LOPES, 2004), torna-se uma balizadora das atitudes genuinamente espontâneas. As gostosuras da infância aparecem no cardápio que oferece aos estudantes, para que saboreiem iguarias literárias segundo conta: 
A leitura vagabunda é aquela que parece quando a gente está num restaurante, aí tem um cardápio. No cardápio tem um bocado de pratos, mas você pergunta ao garçom o que é que tem de ingredientes no prato, né... Então, eu ia falando os ingredientes... vendendo o peixe...falando este livro é assim, aquele é assado. Quem trabalha com leitura tem que conhecer o acervo e o leitor. (FADA SORRISO).

\section{O saber intuído e a mediação didática lúdica}

A didática do sensível tem um papel central como um dos eixos de formação do professor (D'ÁVILA, 2016) e na relação ensino e aprendizagem. Dessa forma, pensamos que o professor que, empoderado pela consciência da mediação lúdica e autoral, exerce a plenitude da presença, conhecendo os recursos sensíveis de sua atividade e das possibilidades que abrem diante de si e do grupo. A partir dessa consciência, parece possuir habilidade de gerar novos leitores, igualmente autônomos e apaixonados. Essa presença que toma a cena de uma contação de história pactua com os ouvintes, pois há, a partir do consentimento dado pela atenção, um acordo tácito que aquieta a alma e os gestos em preparação clara para uma fruição que é proposta e aceita. O ritmo da voz, o timbre, as modulações em uma esquina da história e um cenário completo vai sendo desenhado na mente do que ouve e sorve em atenção focada e em suspense.

As características do lúdico também estão presentes nas características da poesia: o ritmo e a simetria linguística, o enigma disfarçado no sentido, as construções das frases e rimas, assim, as suas réplicas atestam que a poesia é jogo, um exato jogo de palavras, que requer a imaginação criadora. A relação entre a ludicidade e a literatura mostra-se completamente entrelaçada. Veja o que diz Huizinga (2001, p. 149): "O que a linguagem poética faz é essencialmente jogar com as palavras. Ordena-as de maneira harmoniosa, e injeta mistério em cada uma delas, de modo tal que cada imagem passa a encerrar a solução de um enigma", assim em breves palavras, temos a possibilidade de imaginar, como no poema de Mário Quintana (1973): "todos esses que aí estão, atravancando o meu caminho. Eles passarão...Eu passarinho!"

Fada Sorriso evidencia na sua fala, as práticas educativas a que teve acesso em ambiente escolar, quando diz: 
Aos nove anos comecei a ler poesia. Castro Alves foi o meu poeta preferido. Memorizava os versos e recitava em voz alta. Eu ensaiava, e com muita desenvoltura recitava para a plateia que ficava encantada. Eu me emocionava com o sofrimento dos escravos quando recitava: 'O escravo calou a fala/ porque na úmida sala/ o fogo estava para apagar/ e a escrava acabou seu canto/ pra não acordar com o pranto/ o seu filhinho a sonhar'. (FADA SORRISO)

Como consequência dessas experiências, Fada Sorriso replica em sala de aula, o mesmo tipo de mediação didática, intencionalmente tomando sobre si a visão do narrador, guardião de segredos e enigmas e se põe como o sábio descrito por Huizinga (2001) para atingir algo que é imperioso à aprendizagem significativa: a inteireza do sujeito com o qual divide a cena ludopedagógica. Em momentos assim, o ouvinte deixa de ser figurante para ser o protagonista do seu próprio aprendizado e da aventura para além do tempo cronológico, acima do que, aparentemente, é em nossas contingências diárias, adentrando no espaço sublime do "era uma vez". Ouvir uma história bem contada torna-se então, na passagem, no cruzar o portal para uma experiência que é única e é coletiva, sempre diversa na construção de sentido pela imaginação. Para Maffesoli (1998) a função da cognição, quando ligada ao prazer estético alcança uma dimensão superior. Isto explica a relação tão próxima entre as memórias lúdicas de leitura de Fada Sorriso e o seu fazer docente, que encontramos imbricados em seu relato:

Tornei-me professora de biologia e de matemática, mas na verdade eu sempre ensinei leitura. Sou uma professora de leitura. A biologia e a matemática são instrumentos que eu utilizo para que se faça uma leitura melhor da natureza e dos sistemas de relação. Tudo pode ser lido e descrito. (FADA SORRISO).

Por estarmos tão acostumados ao silenciamento da linguagem sensível que agrega o pensamento e a construção do conhecimento em interações que envolvam o corpo e a emoção, se torna vaga e aflitiva a noção de uma mediação lúdica criativa, genuína e autoral. Para resolver este impasse, precisamos pensar a aquisição do saber, como um processo que necessita de sua dimensão relacional e mutante, dessa forma, o professor tem em si uma gama de saberes e também oportunidades de saber - as suas ignorâncias. Nas palavras de Zen (2007) "a prática docente é palco desses tantos confrontos e diálogos que montam a cena 
cotidiana da sala de aula", não há meros executores de tarefas, mas criadores na relação pedagógica. O desejo pode alavancar a motivação correta e completar o ciclo do ato de aprender. D'Ávila (2014) esclarece ainda mais e potencializa a necessidade de mudança na abordagem da aquisição do saber em que criatividade e autoria são instâncias estruturantes na ação educativa e necessita de um trabalho com base em linguagens artísticas.

No processo de sensibilização pela arte, há um mergulho necessário e profundamente pessoal: o eu lúdico precisa aflorar numa caminhada inicial para si mesmo e como num círculo virtuoso, em um retorno, que abarque a complexidade e potencialidade de cada um. Não se chega a um intelecto superior sem que se passe pelo corpo e suas emoções.

Se o aprender dá-se também no corpo, em todos os seus sentidos e não somente no nível mental, é possível inferir que a autoeducação ludoestética do professor seja um processo contínuo que necessita passar pela leitura literária. Parece improvável, mediar com arte, sem que estas mesmas dimensões artísticas tenham sido experimentadas de forma pessoal pelo professor. Assim, ao trilhar o caminho da didática do sensível, o professor tem na sua própria história de eterno aprendiz, este estado de prontidão e sensibilidade que irá fluir para o estudante, sem que haja lacuna entre o que é conhecido (conhecimento) e o que é vivenciado (vida). Este elo perdido entre o processo didático que anestesiou os sujeitos do processo, estudantes e professores, para D'Ávila (2014) reside na arte como linguagem com potência equalizadora dos saberes didáticos pedagógicos e do saber ludo-sensível.

Assim, está proposto ao professor, fazer aflorar um saber mais orgânico que é construído horizontalmente, em trocas mais efetivas e conscientes, em ambiência de afetividade lúdica. Essa segurança psicológica proporcionada pela aceitação da dimensão subjetiva inerente ao sujeito poderá reforçar a desenvoltura profissional, mediante uma didática liberadora de potenciais latentes. Essa relação que estabelece um saber orgânico e dinâmico pode ser analisada na experiência relatada por Pequeno Príncipe:

Eu já vi estudantes problemas mudarem de rota e progredirem nos estudos. Procuro ter um relacionamento amigável com meus estudantes independentemente da escola que eu trabalhe. Eu me aproximo e acabo conquistando a confiança. Esse é um dos papéis do educador. Eu sou um professor incentivador e falo com muito

revista entreideias, Salvador, v. 7, n. 1, p. 153-170, jan./jun. 2018165 
orgutho e não me importa se venho a incomodar a $A, B$, ou $C$ por conta do meu perfil. Meus estudantes, a maioria, são meus amigos no Facebook. Eu os estimulo muito e eles vão adiante nos estudos (PEQUENO PRÍNCIPE).

Finalmente, alargar o pensamento criativo como impulsionador de ciclos virtuosos, de formação e empoderamento do professor parece ser um objetivo desejável. Tardif (2002) considera de extrema importância que professores se posicionem e expressem as ideias sobre o desenvolvimento dos saberes e de seus modos de ensino para o bem de todo o corpo docente.

Num dos últimos encontros que tivemos para observação participante, Pequeno Príncipe abre a aula falando da importância de ter regras para a vida: "[...] buscar conhecimento para ter uma vida socialmente saudável na leitura autodidata. Sem esperar pelos outros ou pela escola. Vocês precisam ter o alvo de ler em inglês também". Os estudantes se empolgam com a palavra do professor e contam que uma colega de outra sala tinha seguido os conselhos e não parava mais de estudar e diziam: "agora ela sabe muito". Nestes encontros de observação participante, pude ter um vislumbre do ensino lúdico que vai além dos conteúdos, com métodos criativos que não dispensam o afeto, o respeito e a viva esperança que como D'Ávila (2007, p. 27) sintetiza tem "[...] o enlevo em se ensinar e, principalmente aprender".

\section{Conclusão}

Vimos a questão de pesquisa envolvendo a potencialidade da mediação lúdica da leitura literária, respondida, na forma descentralizada e fluída com que os professores organizam as memórias e as práticas leitoras, bem como as partilhas do que lhes é caro. Assim, constatamos que o "eu lúdico", enquanto impulso inicial do sujeito mostrou-se acionador de habilidades e competências que, mediante contínuas experiências afetivas com a leitura literária, enraíza a identidade e fornece asas para voos acima das cercas impostas pela profissão e expectativas sociais. Essa exposição às leituras e a todo um universo imaginado concretiza um perfil profissional, que, por sua vez, influencia a forma e a qualidade das mediações didáticas. Os professores pesquisados, embora amantes da literatura não submetem os estudantes nem ao diletantismo literário, nem ao acréscimo de conteúdo a respeito de leitura, 
antes, são guiados por uma sensibilidade tal, que os faz agir com humanidade, ética e arte diante das limitações impostas a esta geração, oferecendo um pouco do que descobriram nos livros. Esse impulso de doar poesia e visão alargada do mundo, que parte de professores-leitores-apaixonados, parece ser acionado por uma postura política de fazer a diferença com o que for possível, numa mediação lúdica que reverbera na autoestima e na cognição dos estudantes, pois o conteúdo não deixará de ser importante, contudo urge saber trata-lo com mais graça, criatividade e ludicidade.

O tema, certamente, carece de novas pesquisas para uma implementação de práticas pedagógicas que tenham, no lúdico e no sensível, uma base para inovações. Podemos afirmar que a ludicidade, nesta pesquisa, mostrou-se um elemento fundante da mediação dos saberes literários, como expressão da satisfação da necessidade de plenitude interior do ser humano. A s histórias de vida de Fada Sorriso e do Pequeno Príncipe são fontes primeiras para as suas práticas docentes, que, em consequência, permite-lhes um alargar da visão e da práxis, ao considerar as necessidades dos estudantes, em todos os aspectos transcendentais, ensejando aportes ao ensino da leitura literária. As atividades desenvolvidas envolvendo a leitura literária possuem um caráter de atividade livre, sem cobrança de notas, portanto, adesão voluntária e de consequências imprevistas, o que revela uma característica basilar do jogo como um círculo mágico. (HUIZINGA, 2001) Os professores pesquisados inserem atividades lúdicas em suas mediações didáticas conforme o estilo próprio a cada sujeito e demonstram que a leitura literária tem um caráter agregador e desenvolvedor de potencialidades humanas, propiciando o amadurecimento das relações afetivas em ambiente e cotidiano escolar.

\title{
The construction of the teacher's profile and the educational mediation of education in Fundamental Teaching li
}

\begin{abstract}
The article brings results of research conducted in 2016 with teachers who had a life history marked by literary reading and, in consequence, establish mediations of reading in school environment in elementary school II. The research was conducted with a teacher and a teacher of public schools, one in Salvador and another in Feira de Santana, through a phenomenological approach using life stories, with the aid of the instruments: participant observation, narrative interview and autobiographical text. The teachers participating in the research are graduates in Biology and Mathematics. Playfulness as the premise of the experience with literary reading in the subjects' lives
\end{abstract}


was investigated, just as their playful expression was observed in didactic mediations and spontaneous sharing of literary knowledge. It was concluded that the "ludic ego", as the initial impulse of the subject, through continuous affective experiences with literary reading, concretizes a professional profile, which, in turn, influences the form and quality of didactic mediations.

Keywords: Literary Reading. Playfulness. Didactic Mediation. Life stories.

\section{Referências}

BARTHES, R. Aula. São Paulo: Cultrix, 1980.

BOSI, E. O tempo vivo da memória. São Paulo: Ateliê Editorial, 2003.

BROUGÉRE, G. Jogo e educação. Porto Alegre: Artes Médicas, 1998.

CALLOIS, R. Os jogos e os homens. Lisboa: Cotovia, 1990.

D'ÁVILA, C. Didática lúdica: saberes pedagógicos e ludicidade no contexto da educação superior. Revista entreideias: educação, cultura e sociedade, v. 3, n. 2, 2014. Disponível em: < http://www.portalseer. ufba.br/index.php/entreideias/article/view/9164/8968 > . Acesso em: 20 out. 2015.

D'ÁVILA, C. Razão e sensibilidade na docência universitária. Revista em Aberto, Brasília, v. 29, n. 97, p. 103- 118, 2016.

D'ÁVILA, C. Educação e ludicidade: ensaios 04. Salvador: Universidade Federal da Bahia: Faculdade de Educação: GEPEL, 2007.

DUARTE JÚNIOR, J. F. O sentido dos sentidos: a educação (do) sensível. Curitiba: Criar, 2000.

DURAND, G. As estruturas antropológicas do imaginário: introdução à arquetipologia geral. Trad. Helder Godinho. São Paulo: Martins Fontes, 1997.

DURAND, G.O imaginário: Ensaio acerca das ciências e da filosofia da imagem. 5. ed. Rio de Janeiro: Difel, 2011.

FREIRE, P. A importância do ato de ler. São Paulo: Cortez, 2001

GOMEZ, M. V. Educação em rede: uma visão emancipadora. São Paulo: Editora Cortês, 2004.

HUIZINGA, J. Homo Ludens: o jogo como elemento da cultura.

São Paulo: Perspectiva, 2001.

LAJOLO, M. Literatura: Leitores \& leituras. São Paulo: Moderna. 2001

LAJOLO, M. Do mundo da leitura para a leitura do mundo. São Paulo: Ática, 2006.

LOPES, C. Ludicidade, contributo para a busca dos sentidos do Humano.

Aveiro: Ed. Univ. de Aveiro, 2004 
LUCKESI, C. C. (Org.). Estados de consciência e atividades lúdicas. In: Ludicidade: onde acontece? Educação e ludicidade: ensaios 3. Salvador: Faculdade de Educação da UFBA: Programa de Pós-Graduação em Educação: GEPEL: Secretaria de Cultura e Turismo, 2004.

LUCKESI, C. C. Desenvolvimento dos estados de consciência e ludicidade. Cadernos de Pesquisa, Salvador, v. 2, n.21, p. 9-25, 1998.

LUCKESI, C. C. Ludicidade e atividades lúdicas: uma abordagem a partir da experiência interna. In: PORTO, Bernadete de Souza (Org.) Educação e ludicidade: ensaios 2: a ludicidade: o que é mesmo isso? Salvador: Faculdade de Educação da UFBA: Programa de Pós-Graduação em Educação: GEPEL, 2002. v. 1.

LUCKESI, C. C. Ludopedagogia: ensaios 1: educação e ludicidade. Salvador: Faculdade de Educação da UFBA:Programa de Pós-Graduação em Educação: GEPEL, 2000. v. 1.

MAFFESOLI, M. Elogio da razão sensível. Tradução de Albert Christophe Migueis Stuckenbruck. Petrópolis, RJ: Vozes, 1998.

MAFFESOLI, M. A transfiguração do político: atribalização do mundo. Porto Alegre: Sulina, 2001.

MAFFESOLI, M. Perspectivas tribais ou a mudança do paradigma social. Porto Alegre (RS), Revista FAMECOS, Porto Alegre, n. 23, p. 23-29, abr. 2004.

MORIN, E. O cinema ou o homem imaginário. Ensaio de antropologia. Lisboa: Moraes Editores, 1970.

PENNAC, D. Como um romance. Tradução de Leny Werneck. 3.ed., Rio de Janeiro: Rocco, 1993.

QUINTANA, Mario. Cadernos H. Porto Alegre: Globo, 1973.

SAINT-EXUPÈRY, A. de. O Pequeno Príncipe. 48. ed., Rio de Janeiro: Agir, 2004

TARDIF, Maurice. Saberes docentes e formação profissional. Petrópolis, RJ: Vozes, 2002.

ZEN, G. C. Confabulações na formação de professores: a experiência e o saber ético como saberes docentes. Salvador: Dissertação (Mestrado em Educação e Contemporaneidade) - Departamento de Educação, Universidade do Estado da Bahia Salvador, 2007.

ZILBERMAN, R. O papel da literatura na escola. Porto Alegre:

Via Atlântica, 2008. n. 14.

Submetido em: 02/04/2017 | Aceito em:19/12/2017 
entreideias_miolo_artigo09.indd 170 